\title{
Interview: Anthony Costello
}

\author{
Climate change represents the biggest health threat of the twenty-first century, \\ according to a new report published 16 May in The Lancet. Olive Heffernan talks \\ to lead investigator Anthony Costello, director of the Institute for Global Health at \\ University College London.
}

How did this study come about? Just over a year ago, The Lancet challenged us to do this study. Back then, climate change was not one of my top priorities. I would have said that dealing with malnutrition and HIV and having a better health service were more important issues in health. But I've changed my perspective now, partly because I'm beginning to notice the effect that rising temperatures are having in certain parts of the globe.

What climate-related health issues can we expect this century?

In a very broad sense, there will be changing patterns of infection. Insectborne diseases like dengue fever, tickborne encephalitis and malaria will spread. We're already seeing blue tongue virus in livestock moving up from southern Europe, for example. But I don't think that infectious disease will be the major health effect of climate change, unless new viruses emerge, which is a great unknown.

\section{The biggest health effect} that will emerge in the next 20 years will be related to food and water security.

Heat is a silent killer. Certainly as average temperatures rise we're going to get many more heat waves and people outside of their coping range. When you get above a certain temperature level, the question is how well can people adapt.

But the biggest health effect that will emerge in the next 20 years will be related to food and water security. There could be quite serious shortages and large rises in food prices, which will penalize the poorest. Currently malnutrition is quite a significant factor in about 60 per cent of childhood deaths. This can result in low birth weight and predisposition to infectious diseases, such as measles, tuberculosis and pneumonia.

What can health professionals do? Firstly, we have to add the voice of the health community to the argument to reduce greenhouse gas emissions. We must campaign urgently on emissions and reforestation. Climate change is going to affect the health of our children and grandchildren, and getting that message across does focus minds. Secondly, we need a framework for tackling this problem.

What exactly would that framework involve?

We need more information. I was shocked to find that there are no health impact assessments on the impacts of climate change in Africa. Not one. The World Health Organization has the tools to do this, but there are very few resources. So we need to start by having country-level health impact assessments for climate change. There's a deficit of data on climate impacts in Africa, but the situation isn't much better in Asia. Beyond that, we need to get down to localities. It's quite important to do participatory work with communities on their risks, and we're interested in launching an initiative to get people to collect their own data.

There are also lots of technological improvements we can make, whether they relate to food production or water storage and conservation. Another aspect will involve northern industrialized countries cutting their luxury emissions rather than their survival emissions. We've got to slash our emissions to get ours down to the level of a country like India. This is going to be a formidable challenge, but we have to highlight the benefits. If we could persuade everyone to take more

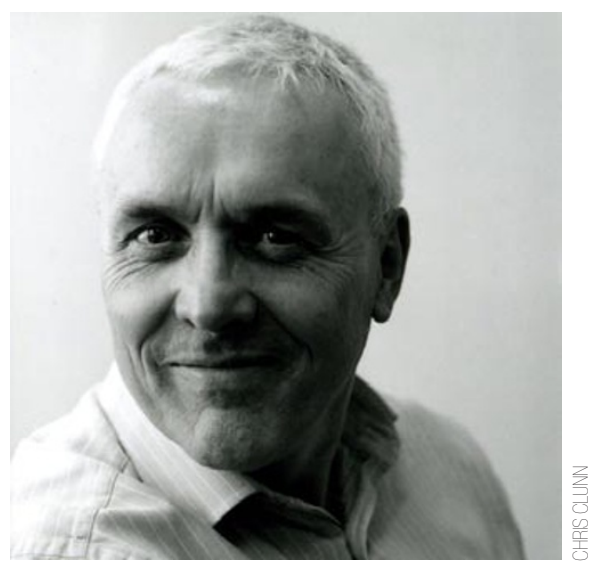

Anthony Costello of University College London.

exercise and cycle to work, for example, then there would be health benefits as well as environmental benefits. And another thing is eating less meat, of course, which would reduce methane emissions from livestock.

How optimistic are you that we can tackle this?

I think we might not get there with technology on a global scale - to clean up the globe is a lot to ask. And have we got enough time to do it? I am fearful of tipping points. There's also an absolute deficit of funding to make this work - the funding for adaptation is pitiful. So this has to become our number-one issue now. But I think there's been a tipping point in public opinion, and if we had a practical, rational action plan then there would be a lot of public support for it.

Published online: 21 May 2009

\section{doi:10.1038/climate.2009.49}

Olive Heffernan is editor of Nature Reports Climate Change. 